Article

\title{
Interval Type-2 Fuzzy Inference System Based on Closest Point of Approach for Collision Avoidance between Ships
}

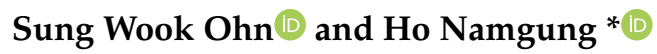 \\ Department of Maritime Transportation System, Mokpo National Maritime University, Mokpo 58628, Korea; \\ ohnsw1012@mmu.ac.kr \\ * Correspondence: ngh2009@mmu.ac.kr; Tel.: +82-64-754-3414
}

Received: 11 May 2020; Accepted: 3 June 2020; Published: 5 June 2020

\begin{abstract}
According to International Regulations for Preventing Collision at Sea, collision avoidance started from assessing the collision risk. In particular, the radar was mentioned as suitable equipment for observation and analysis of the collision risk. Thus, many researches have been conducted by utilizing the radar. Fuzzy Inference System based on Type-1 Fuzzy Logic (T1FIS) using Distance to Closest Point of Approach $\left(D_{C P A}\right)$ and Time to Closest Point of Approach $\left(T_{C P A}\right)$ computed via the radar has been largely used for assessing the collision risk. However, the T1FIS had significant limitations on the membership function not including linguistic and numerical uncertainties. In order to solve the issue, we developed the Fuzzy Inference System based on Interval Type-2 Fuzzy Logic (IT2FIS) as follows: (i) the T1FIS was selected among proposed methods based on the type-1 fuzzy logic; (ii) we extended the T1FIS into the IT2FIS by gradually increasing the Footprint of Uncertainty (FOU) size taking into consideration symmetry, and (iii) numerical simulations were conducted for performance validation. As a result, the IT2FIS using the FOU size " $\pm 5 \%$ " (i.e., interval $10 \%$ between upper membership function and lower membership function) not only computed the appropriate and linear collision risk index smoothly until near-collision situation but also help to overcome uncertainties that exist in real navigation environments.
\end{abstract}

Keywords: collision risk; fuzzy inference system; type-2 fuzzy logic; footprint of uncertainty; near-collision; ship safety domain

\section{Introduction}

Recently, the possibility of maritime collision accidents has been increasing due to the emergence of large ships, high speed, and the growth of maritime transportation and international trade. Thus, the scale of maritime accidents becomes larger and it causes serious marine pollution, huge economic losses, and loss of life at sea. According to statistic investigation presented by Korean Maritime Safety Tribunal (KMST) [1] over the past five years, collision accidents among entire accidents at sea have reported approximately $13.5 \%$. In particular, more than approximately $90 \%$ out of collision accidents was due to human errors. Most of these human errors were a "lack of recognition of collision risk". According to "Rule 7: Risk of Collision" in the International Regulations for Preventing Collision at the Sea (COLREGs) [2], the collision risk must be assessed by all available means appropriate to the prevailing circumstance using predictive technology. In particular, the radar having the Automatic Radar Plotting Aid (ARPA) function, which can obtain plots of detected objects, equivalent systematic observations, Distance to Closest Point of Approach $\left(D_{C P A}\right)$, and Time to Closest Point of Approach $\left(T_{C P A}\right)$, was referred to as an appropriate equipment to obtain early warning of the collision risk in the COLREGs. Therefore, while nearly four decades since the radar appeared, representative two types of 
static and dynamic assessment methods on the collision risk have been actively utilizing. As for static assessment methods, the term of a ship safety domain was first proposed by Fujii and Tanaka [3] to deal with the safe navigation ships. At this time, safe boundary taking into consideration the distance from the center ship must keep the area of evasion from the overlapping of other ship's safety domain. This concept of similar definitions can be found in [3-10] applying a different size and shape of the safe boundary. Strength is that the navigator may feel intuitional and comfortable analyzing what spacing around an approaching ship via a graphical shape [11]. However, weakness is that the ship safety domain would not only require complex and frequent reconfiguration according to different types of water areas, but also could not quick computational collision risk and decision-making in dynamic changing circumstances due to only taking account of the ship's length as a parameter [11].

Hence, a number of researches assessing the collision risk via Collision Risk Index (CRI) have been conducted [12-19]. The CRI is to aggregate dynamic parameters into just one number, and in terms of computational time and quick decision-making, it is faster than ship safety domain. In particular, Hasegawa [15] developed the Fuzzy Inference System (FIS) for computing the CRI based on type-1 fuzzy logic. For this, navigator interviews were used to connect $D_{C P A}$ and $T_{C P A}$ to the $C R I$. In $[16,18]$, on the basis of [15], fuzzy membership functions using $D_{C P A}$ and $T_{C P A}$ were created by using dimensionless values with the ship length and velocity or adding another input parameter. However, the Fuzzy Inference System based on the type-1 fuzzy logic (T1FIS) was pointed out that membership functions only depended on empirical factor due to navigator interviews $[17,19]$. Thus, membership functions of $D_{C P A}$ and $T_{C P A}$ were determined on the basis of virtual navigation situation resulting from the maneuverability of the Own-Ship (OS) using K-T (i.e., index of turning ability and index of responsiveness to the helm) equations [17] and near-collision situation data using the ship safety domain [19].

Nonetheless, the T1FIS has the following significant limitations. The membership functions of $D_{C P A}$ and $T_{C P A}$ were created as a crisp degree according to the linguistic variables obtained average values via navigator interviews, ship maneuverability, and near-collision data. These values included errors and did not take into account numerical uncertainties in changing circumstances that may take place at the actual sea area in which a number of ships with different maneuverability were dynamically navigated. Accordingly, the T1FIS did not compute appropriate $C R I$ according to numerical changing of $D_{C P A}$ and $T_{C P A}$ in order that navigator could take an action for collision avoidance at optimal distance and time [15-19]. Therefore, in case the Target-Ship (TS) is approaching to the OS, it would cause that navigator may have difficulty to make an optimal decision for taking an action for collision avoidance based on positioning and timing accuracy.

Unlike the type-1 fuzzy logic, the type-2 fuzzy logic [20-22], which consisted of fuzzy degrees of membership that can take into consideration uncertainties, can help to overcome uncertainties that exist in real changing circumstances. In particular, Fuzzy Inference System based on the Interval Type-2 Fuzzy Logic (IT2FIS) in mobile navigation requiring positioning and timing accuracy in a dynamic and unknown environment prevented random errors that change unpredictably, and consequently, taking an action for collision avoidance at optimal distance and time showed smooth trajectory, reduction of path deviation, and saving time [23-29]. At this time, the interval type-2 membership functions are created from deviation of the parameters of the original type- 1 membership functions by a percentage of the universe of discourse of the variables that they are associated to. However, these did not take into consideration systematic way of determining uncertainties on membership function. Hence, the application of appropriate uncertainties is needed to develop the IT2FIS.

In this paper, we propose the IT2FIS in order that the navigator can obtain appropriate CRI in unknown and dynamic circumstances for purpose of efficient taking an action for collision avoidance. This paper has essentially two parts: In the first part, the IT2FISs are generated by gradually increasing the uncertainty size taking into consideration symmetry over a number of steps. In the second part, from the beginning of the encounter situation to the collision situation, the IT2FISs are observed and compared how well the appropriate $C R I$ is being computed according to changing $D_{C P A}$ and $T_{C P A}$ at 
optimal positioning and timing. At this time, because the number of collision accidents was very few, near-collision, in which there is the danger of collision between ships approaching each other, but with no collision eventually occurring, is used.

The remainder of the paper is organized as follows: Section 2 describes collision avoidance method based on the collision risk. Section 3 presents the IT2FISs using different uncertainty size. In Section 4, numerical experimental results and discussion are conducted. Finally, a summary of the work and the conclusion are drawn in Section 5.

\section{Collision Avoidance Method}

Figure 1 shows the collision avoidance procedure in accordance with the COLREGs, and the following subsection could be four steps [2]. Firstly, the TS and/or obstacle in the vicinity of the OS are detected by using radar plotting according to "Rule 5". Secondly, the collision risk is assessed on the basis of the computed CRI according to "Rule 7". Thirdly, encounter relation is decided according to "Rule 13", "Rule 14", and "Rule 15". Finally, taking an action for collision avoidance via optimal course and speed taking into consideration the collision risk is executed by a control command according to "Rule 8", "Rule 16", and "Rule 17".

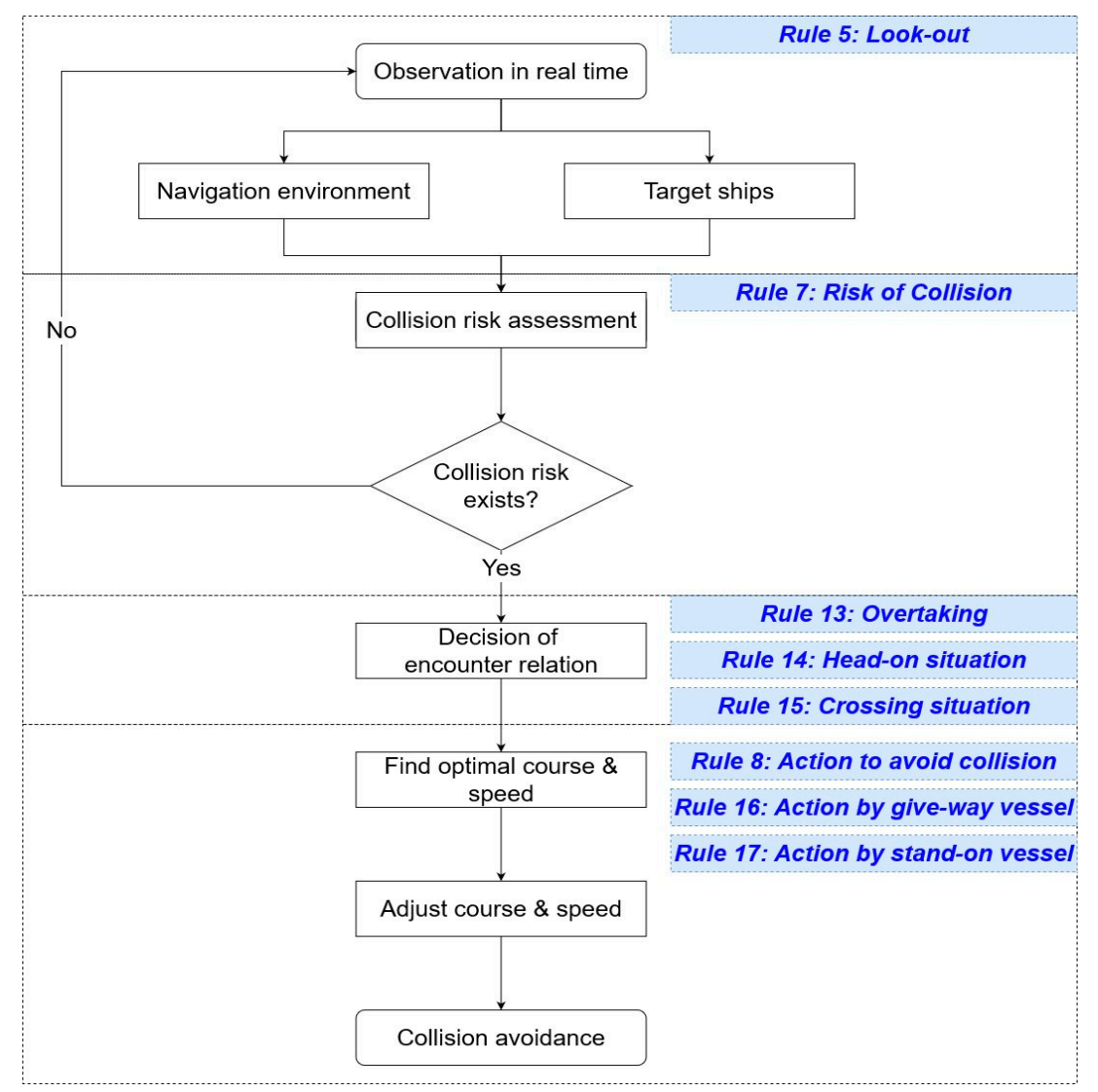

Figure 1. Procedure for collision avoidance in accordance with the International Regulations for Preventing Collision at the Sea (COLREGs).

\subsection{Assessment Methods on the Collision Risk}

\subsubsection{Ship Safety Domain}

A number of domain models using a different shape and size have been developed with time. Early model was on the basis of statistical process via the radar data for purpose of preventing collision and determining capacity of local waterways $[3,4,6,9,10]$. After this, navigator's knowledge [7] and 
analytical approach $[5,8]$ were utilized for the purpose of collision risk analysis and collision avoidance. In practice, using a ship safety domain in an encounter situation between the OS and the TS can be divided into four as shown in Figure 2.

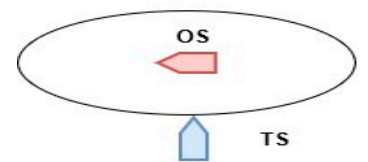

(a)

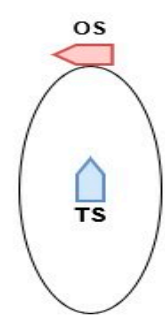

(b)

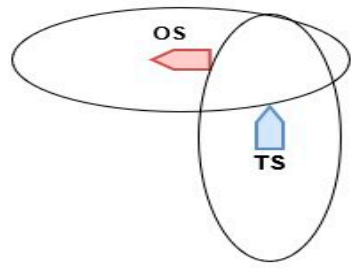

(c)

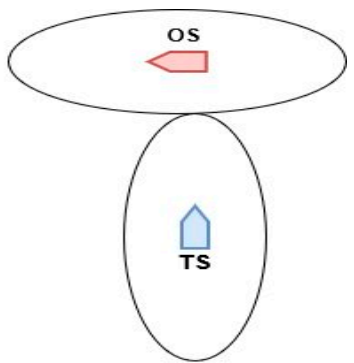

(d)

Figure 2. Different safety criterion of ship safety domain: (a) Own-Ship (OS) domain is not violated; (b) Target-Ship (TS) domain is not violated; (c) neither OS nor TS domain is violated, and (d) both domains do not overlap.

Recently, the research for suitable determination of size and shape of ship safety domain was conducted on the basis of the Automatic Identification System (AIS) traffic data from Fehmarn belt strait [9]. As a result, size and shape were roughly similar to the ship safety domain, which is an ellipse with a long radius of $4 \mathrm{~L}$ and short radius of $1.6 \mathrm{~L}$ ( $\mathrm{L}$ is ship length), proposed by Fujii and Tanaka as shown in Figure 3. Their application scope was to detect near-collision situations and waterway risk analysis. The present study thus considered the near-collision situation using the ship safety domain introduced by Fujii and Tanaka for the purpose of verification of the appropriated CRI computed from the IT2FIS. At this time, safety criterion of ship safety domain was used by Figure $2 \mathrm{~d}$.

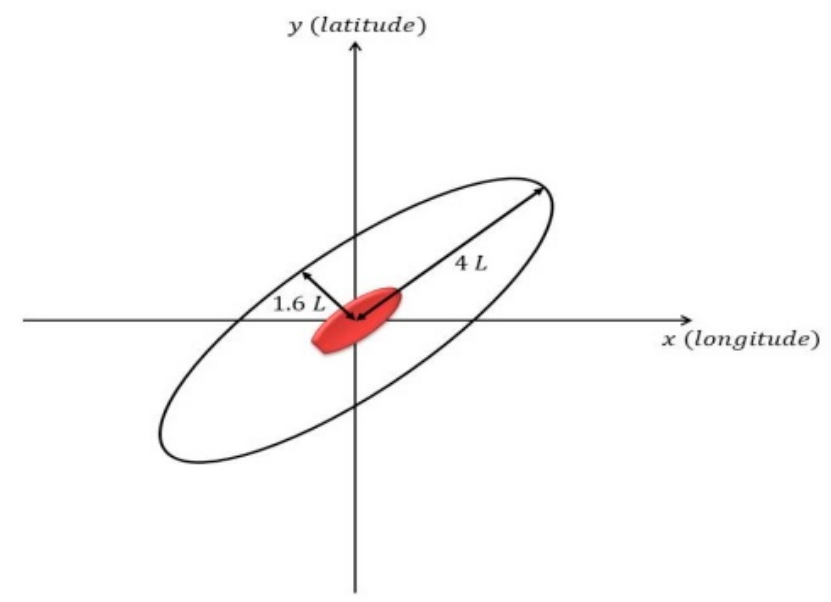

Figure 3. Ship safety domain proposed by Fujii and Tanaka.

\subsubsection{Closest Point of Approach}

The closest point of approach, also known as CPA, is the point where the OS is closest to the TS at any time. Current position, course, and velocity for both the OS and the TS were used in order to compute CPA as shown in Figure 4. 


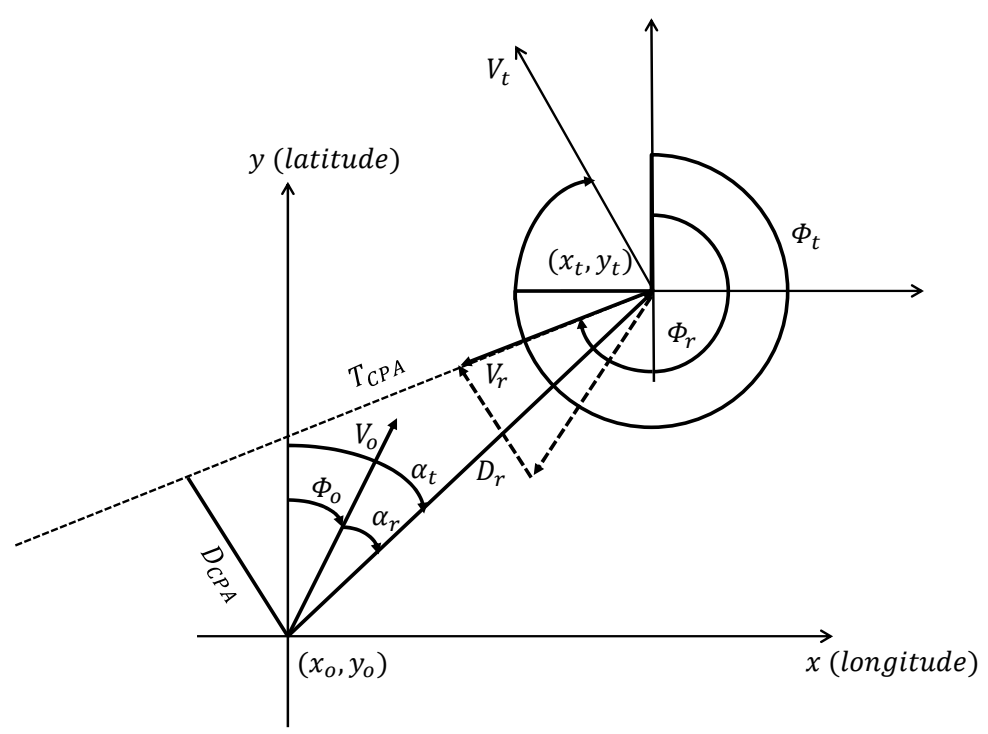

Figure 4. Illustration of the closest point of approach.

Position, course, and velocity of the OS are given as $\left(x_{0}, y_{0}\right), \Phi_{0}$, and $V_{0}$. Likewise, position, course, and velocity of the TS are given as $\left(x_{t}, y_{t}\right), \Phi_{t}$, and $V_{t}$. The relative moving parameters can be computed as

$$
\begin{gathered}
D_{r}=\sqrt{\left(x_{t}-x_{o}\right)^{2}+\left(y_{t}-y_{o}\right)^{2}} \\
V_{r}=V_{o} \times \sqrt{1+\left(\frac{V_{t}}{V_{o}}\right)^{2}-2 \times \frac{V_{t}}{V_{o}} \times \cos \left(\Phi_{o}-\Phi_{t}\right)} \\
\Phi_{r}=\cos ^{-1} \times\left(\frac{V_{o}-V_{t} \times \cos \left(\Phi_{o}-\Phi_{t}\right)}{V_{r}}\right)
\end{gathered}
$$

where $D_{r}$ denotes the relative distance between the OS and the TS, $V_{r}$ denotes the relative velocity, $\Phi_{r}$ denotes the relative course. The distance between the OS and the TS at CPA and the time until CPA are computed as

$$
\begin{gathered}
D_{C P A}=D_{r} \times \sin \left(\Phi_{r}-\alpha_{t}-\pi\right) \\
T_{C P A}=D_{r} \times \cos \left(\Phi_{r}-\alpha_{t}-\pi\right) / V_{r}
\end{gathered}
$$

where $D_{C P A}$ is the distance between the OS and the TS, and $T_{C P A}$ is the time to closest point of approach at that time, $\alpha_{t}$ denotes the azimuth of the TS, and $\alpha_{r}$ denotes the relative bearing.

\subsubsection{Type-1 Fuzzy Inference System}

The linguistic representation and subjective concept like the collision risk originating in the imprecise and vague meaning of words can be dealt from the fuzzy logic [30]. Hence, in order to prevent the collision accidents at sea, the $C R I$ was computed by $D_{C P A}$ and $T_{C P A}$ using fuzzy reasoning [15-19]. In particular, the Type-1 Fuzzy Inference System based on Near-Collision (T1FIS-NC) consisted of the Sugeno fuzzy logic based near collision data via Adaptive Neuro Fuzzy Inference System (ANFIS) [19]. At this time, non-dimensionalized input parameters $D_{C P A} / L, T_{C P A} /(L / V)$ via ship length $(L)$ and ship velocity $(V)$ were used. Figure 5 shows membership functions (Collision, Danger, Threat, and Attention) with linguistic variables. 


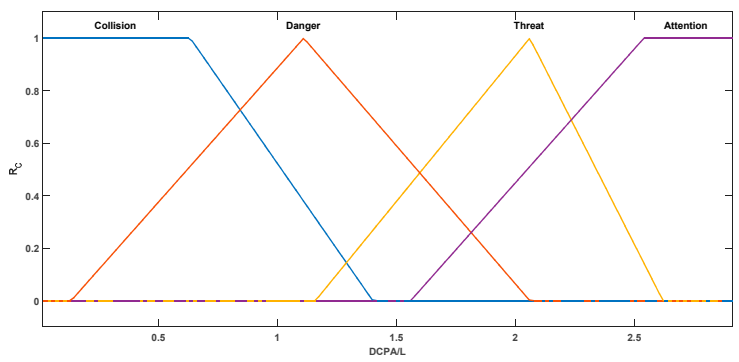

(a)

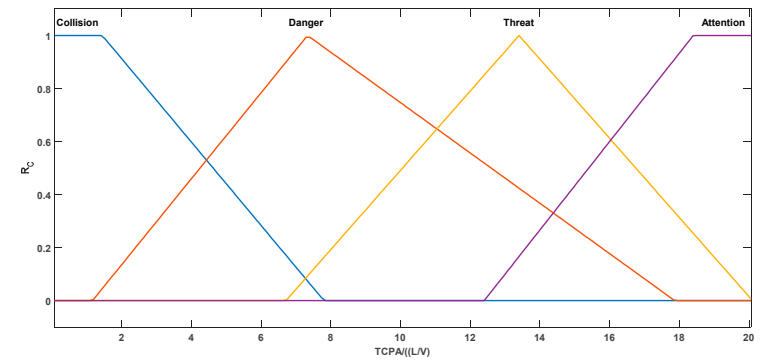

(b)

Figure 5. Membership function of the Type-1 Fuzzy Inference System based on Near-Collision (T1FIS-NC): (a) $D_{C P A} / L$ and (b) $T_{C P A} /(L / V)$.

$D_{C P A} / L$ and $T_{C P A} /(L / V)$ were used for antecedent parameter $x_{1}, x_{2}$, and $R_{c}^{i}$ was used for the consequent parameter. Fuzzy inference rules of T1FIS-NC were composed as

$$
\text { Rule }_{i} \text { : if } x_{1} \text { is } \mu_{\left(D_{C P A} / L\right) i} \text { and } x_{2} \text { is } \mu_{\left(T_{C P A} / \frac{L}{V}\right) i} \text { then } R_{c}^{i}=k_{0}^{i}+k_{1}^{i} x_{1}+k_{2}^{i} x_{2}
$$

where $k_{0}^{i}, k_{1}^{i}, k_{2}^{i}$ are fuzzy sets of the consequent part assigned from the T1FIS-NC. Accordingly, Table 1 presents a total of fuzzy inference rules, consisting of a combination of linguistic variables for each membership function.

Table 1. Components of the fuzzy inference rules for the T1FIS-NC.

\begin{tabular}{cccccccc}
\hline Rule $_{\boldsymbol{i}}$ & Rule $_{1}$ & Rule $_{2}$ & Rule $_{3}$ & $\ldots$ & Rule $_{14}$ & Rule $_{15}$ & Rule $_{16}$ \\
\hline$D_{C P A} / L$ & Collision & Danger & Threat & $\ldots$ & Attention & Collision & Danger \\
$T_{C P A} /(L / V)$ & Collision & Threat & Danger & $\ldots$ & Threat & Attention & Collision \\
\hline
\end{tabular}

Figure 6 shows surface based on a total 16 of fuzzy inference rules, and the CRI (i.e., $R_{c}$ ) can be computed from 0.0 to 1.0 via the fuzzy inference table as presented in Table 2.

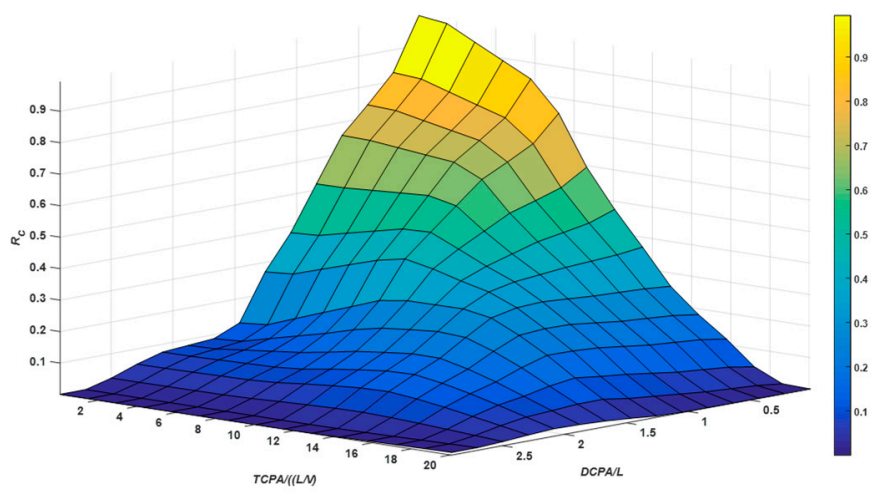

Figure 6. Surface of the T1FIS-NC.

Table 2. Fuzzy inference rule of the T1FIS-NC.

\begin{tabular}{ccccc}
\hline \multirow{2}{*}{$\boldsymbol{D}_{C P A} / L$} & Collision & Danger & Threat & Attention \\
\cline { 2 - 5 } & 0.994 & 0.773 & 0.477 & 0.021 \\
Collision & 0.777 & 0.662 & 0.401 & 0.017 \\
Danger & 0.395 & 0.423 & 0.335 & 0.015 \\
Threat & 0.062 & 0.246 & 0.152 & 0.011 \\
Attention &
\end{tabular}




\subsection{Avoiding Action in Encounter Situations}

\subsubsection{Encounter Situations between Ships}

It is important that one's maneuver makes surrounding ships understand. Otherwise, it could cause the confusion because it makes surrounding ships uncertain. Therefore, it is necessary that all taking an action for collision avoidance are clear and precise in accordance with the COLREGs.

An evasive maneuver for collision avoidance can be divided into overtaking, head-on and crossing, and encounter situations can be judged with relative bearing according to [2,31]. A ship shall be deemed to be overtaking when coming up with the other ship from a direction more than 22.5 degrees abaft its beam. Head-on situation shall be deemed when a ship could see the masthead lights of the other ship in a line or nearly in a line and/or both sidelights. According to the COLREGs, at least the required minimum intensity shall be maintained at all angles from 6 degrees above to 6 degrees below the horizontal. Consequently, the other ship approaching within \pm 6 degrees by the standard of a ship could be considered as a head-on situation. The crossing situation could be defined that two ships are crossing involving the collision risk. At this time, the angle is between the head-on situation and overtaking situation. Figure 7 presents the different COLREGs situation by its angles.

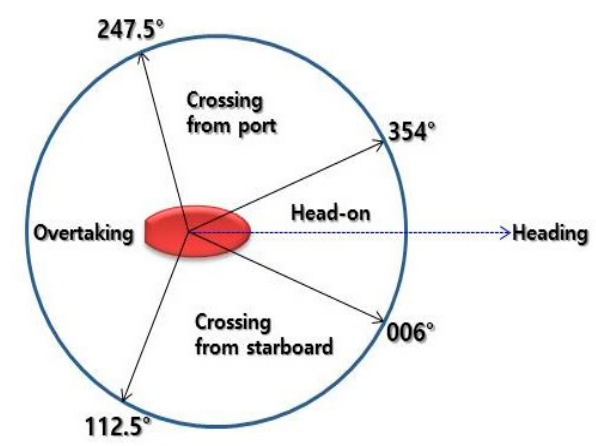

Figure 7. The boundary between the different COLREGs situations.

According to a result of the above, taking an action for collision avoidance in different situations should be as follows:

- Overtaking: The ship being overtaken should keep the present course and speed, and overtaking ship can pass the other ship on the both sides as shown in Figure 8a.

- Head on: Both ships should avoid collision by changing the course to the starboard as shown in Figure $8 b$.

- Crossing: A give-way vessel having the other ship on its starboard side should change its course, and the other ship should keep the present course and speed as shown in Figure 8c.

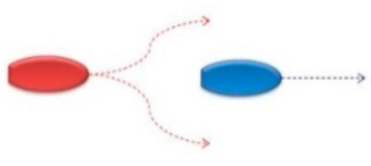

(a)

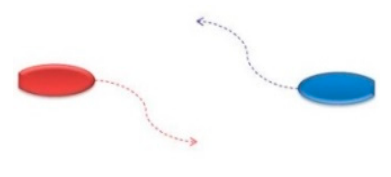

(b)

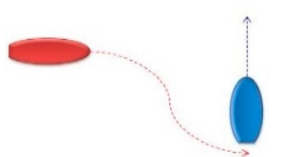

(c)

Figure 8. The path of steering for collision avoidance in the COLREGs situations: (a) Overtaking; (b) head-on situation, and (c) crossing situation.

\subsubsection{Avoiding Action Strategy}

The OS should start avoiding when $R_{c}$ exceed more than the threshold [19]. The T1FIS-NC designated threshold 0.33 for the give-way vessel and more than 0.66 for a stand-on vessel. When 
detecting the collision risk reaches to a pre-designated threshold, the give-way vessel should take an action for collision avoidance normally by changing course to the starboard side. At this time, the stand-on vessel must keep the present course and speed. Additionally, then, the give-way vessel should pass through the stand-on vessel in a state not exceeding 0.66 . When $R_{c}$ disappears, the give-way vessel could return to the original path. In case of exceeding more than 0.66 , both ships must conduct the best cooperation action for collision avoidance. Figure 9 and pseudo-code show taking an action for collision avoidance and returning path according to the $R_{c}$.

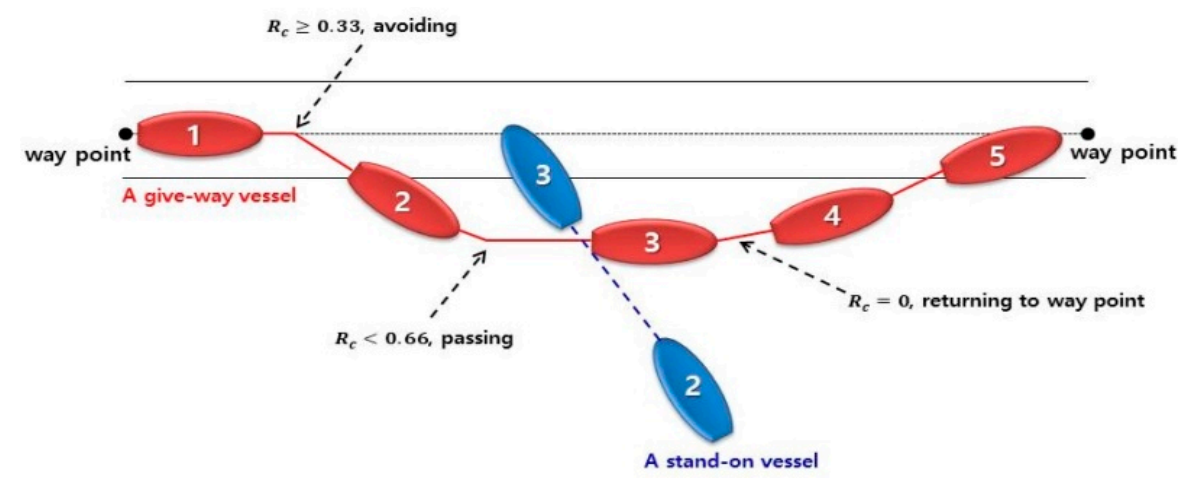

Figure 9. Procedure of collision avoidance according to the $R_{c}$.

Pseudo-code for collision prevention algorithms between the OS and the TS (Algorithms 1 and 2).

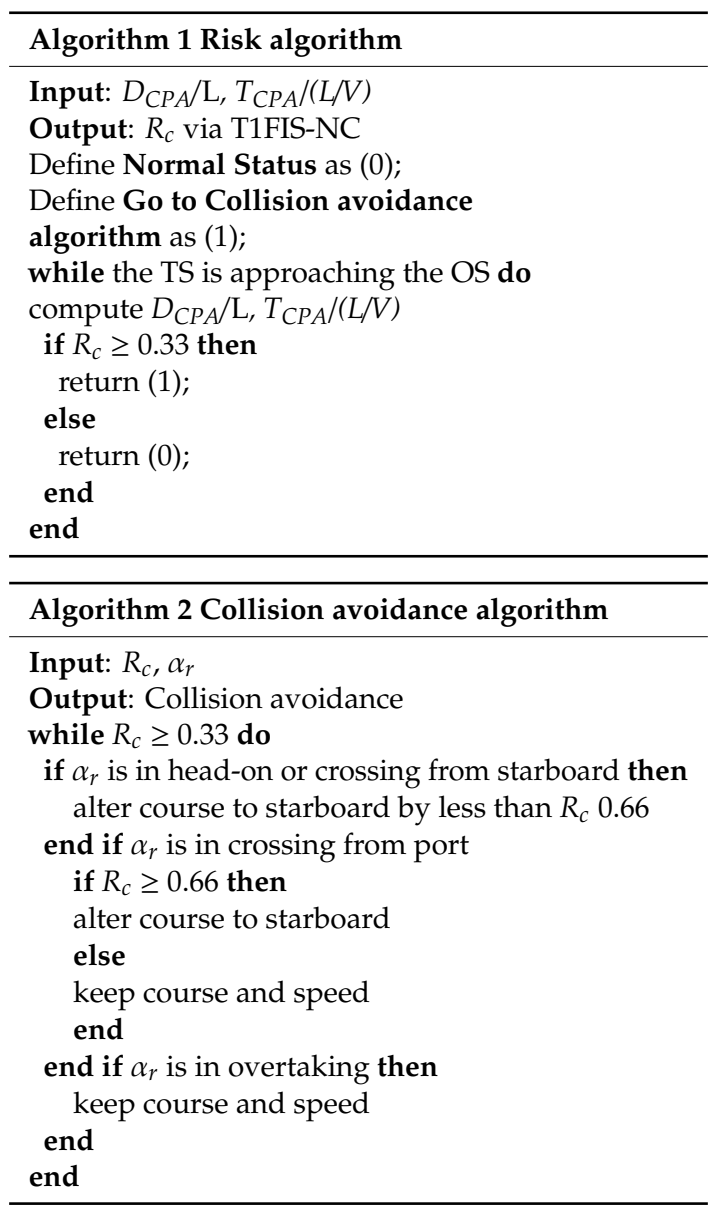




\section{Development of Interval Type-2 Fuzzy Inference System for Collision Avoidance}

The concept of the type-2 fuzzy set proposed by Zadeh [20] is an extension of the type-1 fuzzy set, which is characterized by membership functions using soft fuzzy boundaries. It can not only provide additional design degrees of freedom, but also be very useful in circumstances where a number of uncertainties are present. Type-1 Fuzzy Logic System (T1FLS) and Type-2 Fuzzy Logic System (T2FLS) have a similar process consisting of four components: a fuzzification unit, a rule base, a fuzzy inference engine, and a defuzzification unit. In particular, the T2FLS has a type reducer, which converts the T1FLS output in order that crisp output can be obtained as shown in Figure 10.

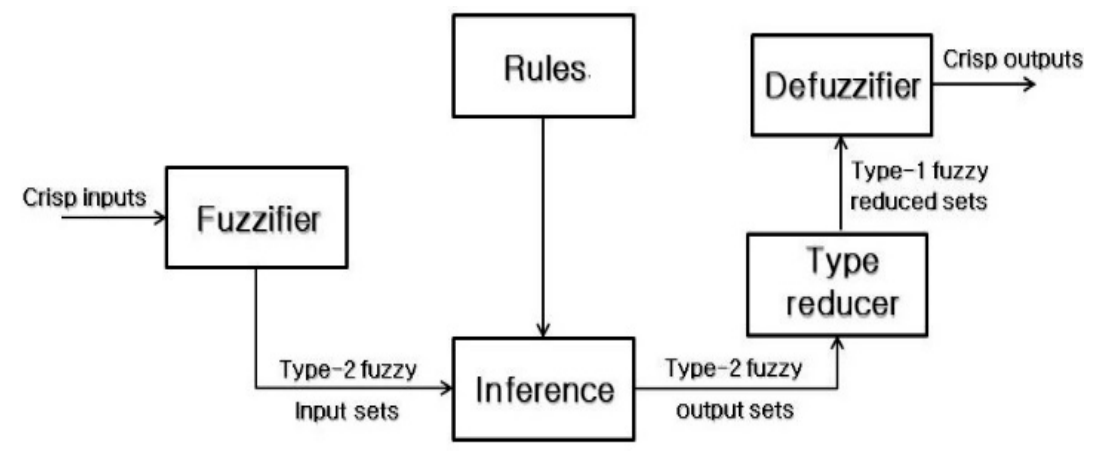

Figure 10. Structure of the type-2 fuzzy logic system.

However, in case membership functions and rule based have been increased, the T2FLS had computational complexity due to type-reduction. Hence, the Interval Type-2 Fuzzy Logic System (IT2FLS) using the iterative Karnik-Mendel (KM) algorithm is being more utilized due to the simplification approach and fast computation than general type-2 fuzzy logic [22]. In particular, IT2FLS can be divided into the Mamdani and TSK system (i.e., the Sugeno fuzzy logic). Therefore, in order to develop the IT2FLS, the following process is necessary:

- Design of an initial T1FLS.

- Extension of the T1FLS into the IT2FLS using the partially dependent design.

This study designated the T1FIS-NC to develop the IT2FIS. At this time, the Interval Type-2 TSK Fuzzy Logic System (IT2FLS-TSK) was utilized due to T1FIS-NC composed by the Sugeno fuzzy logic, and then the IT2FISs were generated by increasing the Footprint of Uncertainty (FOU) sizes taking into consideration symmetry over a number of steps. The reason why the FOU sizes are increased over a number of steps is due to not strong relationship between the IT2FIS performance and the expanding FOU sizes [24]. Hence, it is necessary to increase the FOU sizes over a number of steps, and the IT2FIS performance should be analyzed according to the FOU sizes.

\subsection{Interval Type-2 Fuzzy Sets}

An interval type-2 fuzzy set, denoted $\widetilde{F}$, is characterized by a type- 2 memberships function $\mu_{\widetilde{F}}(x, u)=1$ as

$$
\widetilde{F}=\left\{\left((x, u), \mu_{\widetilde{F}}(x, u)\right) \mid \forall x \in X, \forall u \in J_{x} \subseteq[0,1]\right\}
$$

where $x$, a primary membership value, has domain $X ; u$, a secondary membership value, has domain $J_{x}$ at each $x \in X$ and $J_{x}$ is the primary membership of $x$ and the secondary grades of $\widetilde{F}$ all equal 7 .

Uncertainty in the primary memberships of the IT2FIS, $\widetilde{F}$, consists of a bounded region "FOU". The Upper Membership Function (UMF) and Lower Membership Function (LMF) of $\widetilde{F}$ are two type-1 membership functions that bound the FOU as

$$
\mathrm{UMF}=\bar{\mu}_{\widetilde{F}}(\mathrm{x}) \equiv \overline{\operatorname{FOU}(\widetilde{F})} \forall x \in X
$$




$$
\begin{aligned}
& \mathrm{LMF}=\underline{\mu}_{\widetilde{F}}(\mathrm{x}) \equiv \underline{\operatorname{FOU}(\widetilde{F})} \forall x \in X \\
& J_{x}=\left\{(x, u): u \in\left[\bar{\mu}_{\widetilde{F}}(\mathrm{x}), \underline{\mu}_{\widetilde{F}}(\mathrm{x})\right]\right\}
\end{aligned}
$$

where $J_{x}$ is the interval type-2 fuzzy set. In order to consist of the appropriate type-2 fuzzy sets, the FOU sizes were increased to " $\pm 5 \%$ " (i.e., interval $10 \%$ between the UMF and the LMF) intervals from " $\pm 0 \%$ " to " $\pm 50 \%$ " by adding a uniform band around the T1FIS-NC membership functions.

\subsection{Interval Type-2 Fuzzy Inference Rules}

In the IT2FIS using two inputs $\left(D_{C P A} / L\right.$ and $\left.T_{C P A} /(L / V)\right)$ as parameter $x_{1}$ and $x_{2}$, and one output as $R_{c}^{i}$ according to the T1FIS-NC, it can be expressed:

$$
\text { Rule }_{i}: \text { if } x_{1} \text { is } \widetilde{F}_{1}^{i} \text { and } x_{2} \text { is } \widetilde{F}_{2}^{i} \text { then } R_{c}^{i}=k_{0}^{i}+k_{1}^{i} x_{1}+k_{2}^{i} x_{2}
$$

where $\widetilde{F}_{1}^{i}, \widetilde{F}_{2}^{i}$ are fuzzy sets of antecedent part assigned from the IT2FIS, $R_{c}^{i}$ is the consequent of the rule $i$ th of the IT2FIS, and $k_{0}^{i}, k_{1}^{i}, k_{2}^{i}$ are fuzzy sets of the consequent part assigned from the T1FIS-NC.

On the basis of the rules, surface of the T1FIS-NC (i.e., FOU size " $\pm 0 \%$ "), which gradually increased FOU sizes over a number of steps, is as shown in Figure 11.

\subsection{Computation of Interval Type-2 Fuzzy Inference System}

The result of the input parameters and antecedent operations contained in the firing set produces an interval type- 1 set as

$$
\begin{array}{r}
F^{i}(x)=\left[\underline{f}^{i}(x), \overline{f^{i}}(x)\right] \\
\underline{f}^{i}(x)=\underline{\mu}_{F_{1}^{i}}\left(x_{1}\right) \star \underline{\mu}_{F_{2}^{i}}\left(x_{2}\right) \\
\overline{f^{i}}(x)=\bar{\mu}_{F_{1}^{i}}\left(x_{1}\right) \star \bar{\mu}_{F_{2}^{i}}\left(x_{2}\right)
\end{array}
$$

where $F^{i}(x)$ is the antecedent of the rule $i$ th, and $f^{i}(x)$ and $\overline{f^{i}}(x)$ are upper and lower membership functions, respectively. " $\star$ " denotes t-norm operator, "minimum" or "product" is used.

Consequent output $R_{c}^{i}$ of the rule $i$ th is also an interval type- 1 fuzzy set and is computed as

$$
R_{c}^{i}=\left[\begin{array}{ll}
r_{c l}^{i}, & r_{c r}^{i}
\end{array}\right]=\int_{r_{c}^{1}} \cdots \int_{r_{c}^{N}} \int_{F^{1}} \cdots \int_{F^{N}} 1 / \frac{\sum_{i=1}^{N} f^{i} r_{c}^{i}}{\sum_{i=1}^{N} f^{i}}
$$

$\mathrm{KM}$ algorithms are employed for exactly computing the end-points of left " $r_{c l}$ " and right " $r_{c r}$ "depending on $R_{c}$ as

$$
\begin{aligned}
& r_{c l}=\frac{\sum_{i=1}^{N} f_{l}^{i} r_{c l}^{i}}{\sum_{i=1}^{N} f_{l}^{i}} \\
& r_{c r}=\frac{\sum_{i=1}^{N} f_{r}^{i} r_{c r}^{i}}{\sum_{i=1}^{N} f_{r}^{i}}
\end{aligned}
$$

Defuzzification of the interval type-2 set is performed using the average of $r_{c l}$ and $r_{c r}$, and the defuzzified crisp output is achieved as

$$
R_{c}=\frac{\left(r_{c l}+r_{c r}\right)}{2}
$$




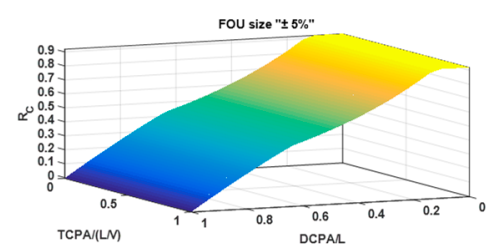

(a)

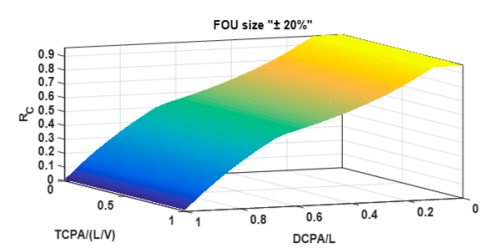

(d)

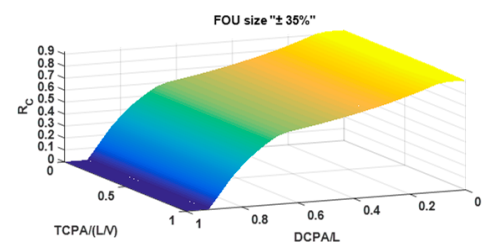

(g)

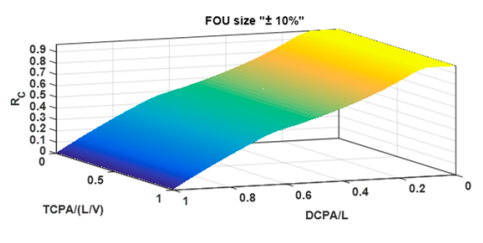

(b)

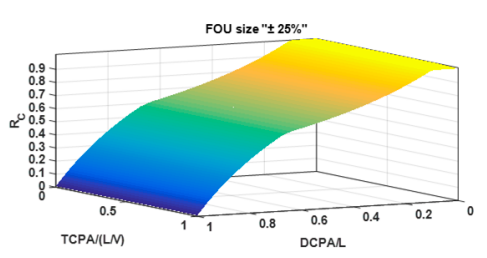

(e)

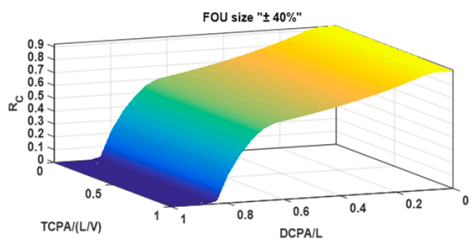

(h)

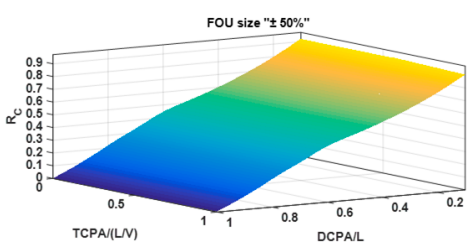

(j)

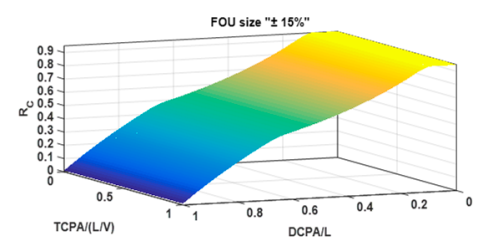

(c)

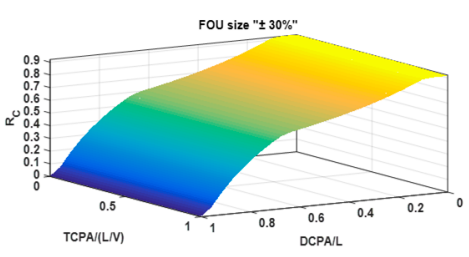

(f)

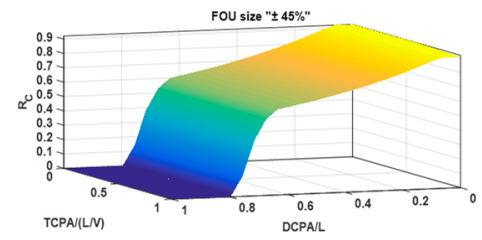

(i)

Figure 11. Surface of the IT2FIS: (a) Footprint of Uncertainty (FOU) size " $\pm 5 \%$ "; (b) FOU size " $\pm 10 \%$ "; (c) FOU size " $\pm 15 \%$ "; (d) FOU size " $\pm 20 \%$ "; (e) FOU size " $\pm 25 \%$ "; (f) FOU size " $\pm 30 \%$ "; (g) FOU size " $\pm 35 \%$ "; (h) FOU size " $\pm 40 \%$ "; (i) FOU size " $\pm 45 \%$ ", and (j) FOU size “ $\pm 50 \%$ ".

Figure 12 shows the summarized process of inference computation on the IT2FIS.

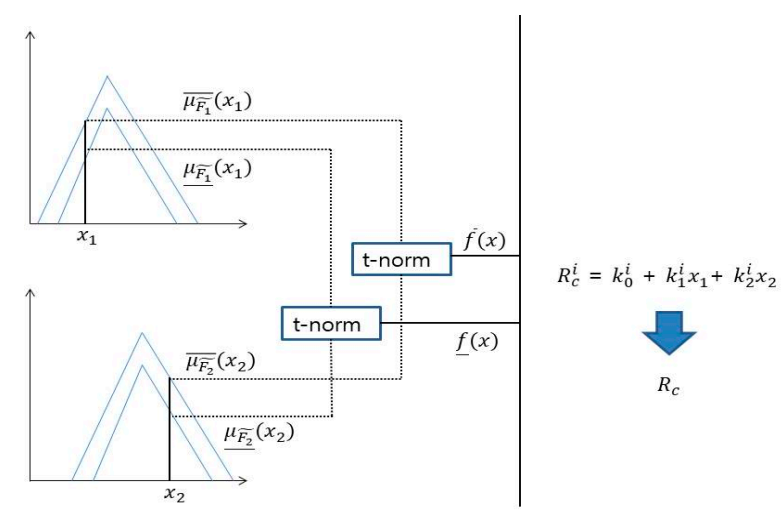

Figure 12. Process of inference computation on the IT2FIS. 


\section{Results and Discussion}

\subsection{Numerical Simulation Results}

In order to validate the performance of the IT2FISs generated by gradually increasing the FOU taking into consideration symmetry over a number of steps, they were applied to near-collision between ships. At this time, one of ships was designated as the OS, and the other was designated as the TS. Navigation information of both ships were extracted from the AIS in Mokpo sea area as presented in Table 3, and Figure 13 shows the occurred area of near-collision, which the ship safety domains proposed by Fujii and Tanaka were overlapped.

Table 3. Initial parameters in numerical simulation.

\begin{tabular}{ccc}
\hline & OS & TS \\
\hline Relative distance & $10.48 \mathrm{~nm}$ & $10.48 \mathrm{~nm}$ \\
Speed & $10.6 \mathrm{kts}$ & $6.3 \mathrm{kts}$ \\
Heading & $49.5^{\circ}$ & $171.6^{\circ}$ \\
Ship length & $75 \mathrm{~m}$ & $67 \mathrm{~m}$ \\
\hline
\end{tabular}

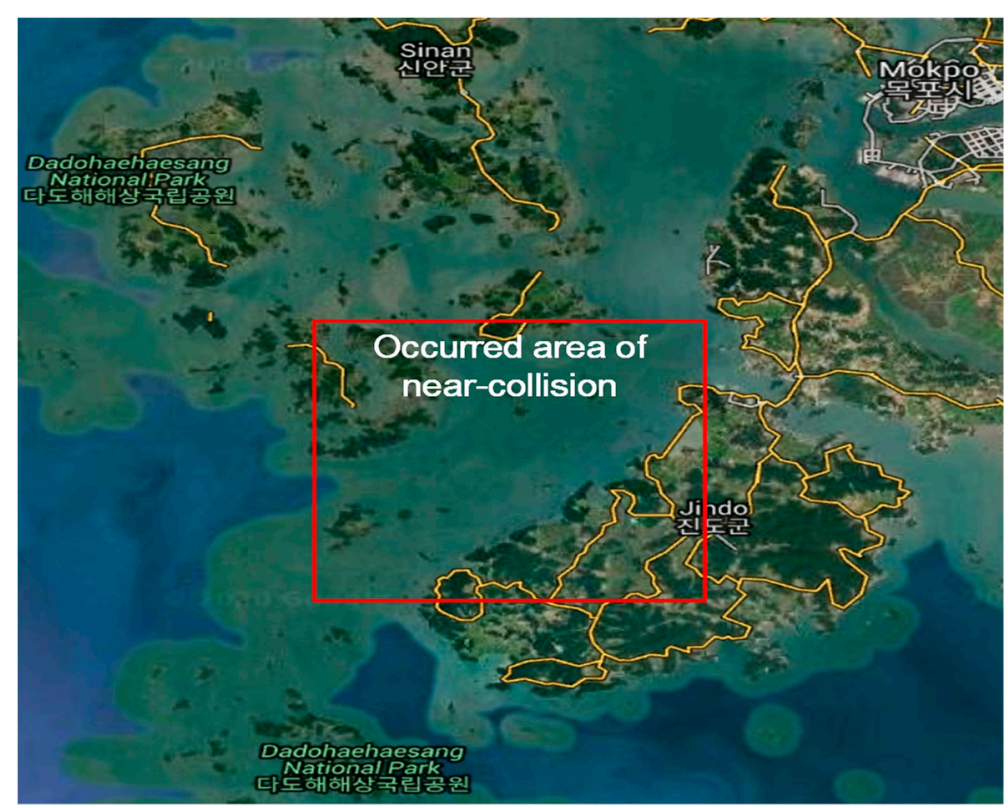

Figure 13. Occurred area of near-collision.

Numerical simulation was conducted based on Matrix Laboratory (MATLAB). Figure 14 shows the encounter situation between the OS and the TS, and near-collision was occurred as presented in Figure 14d. 


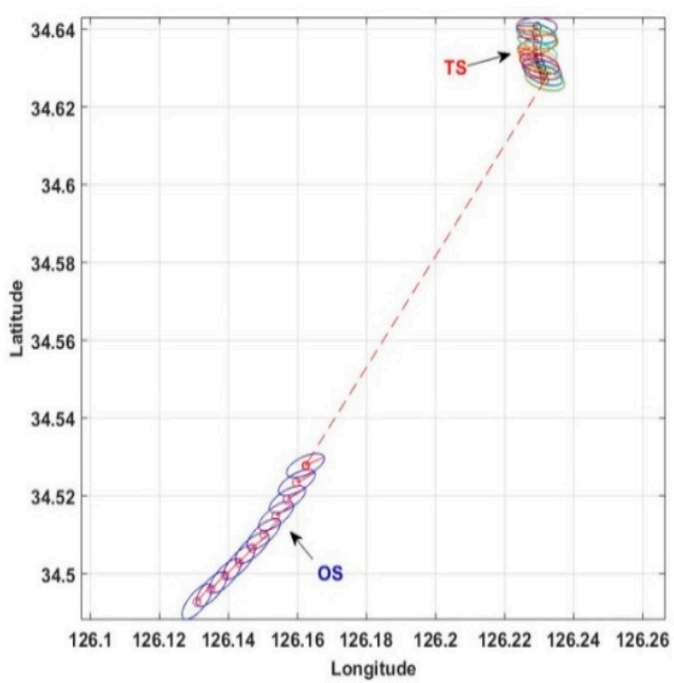

(a)

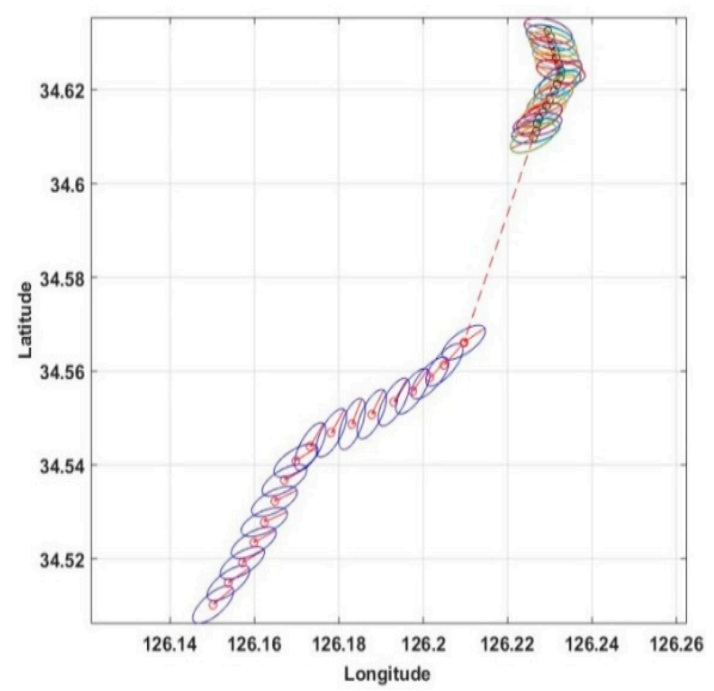

(c)

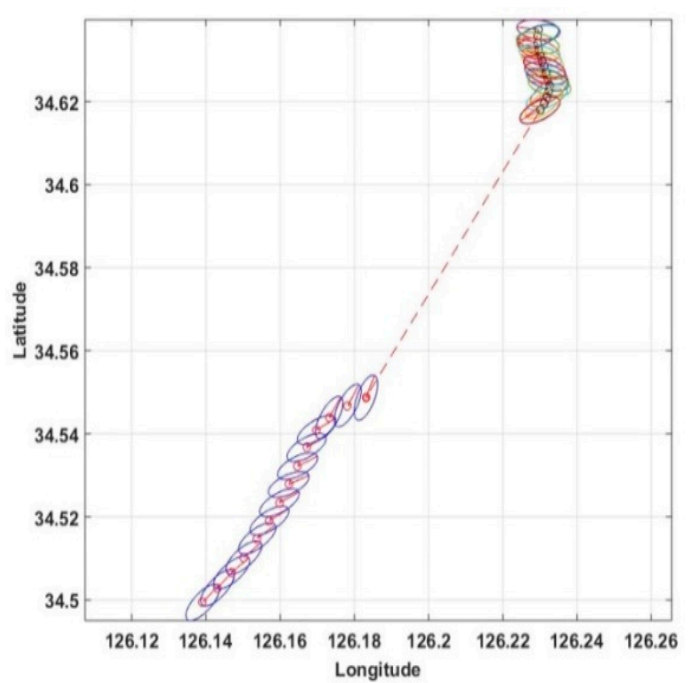

(b)

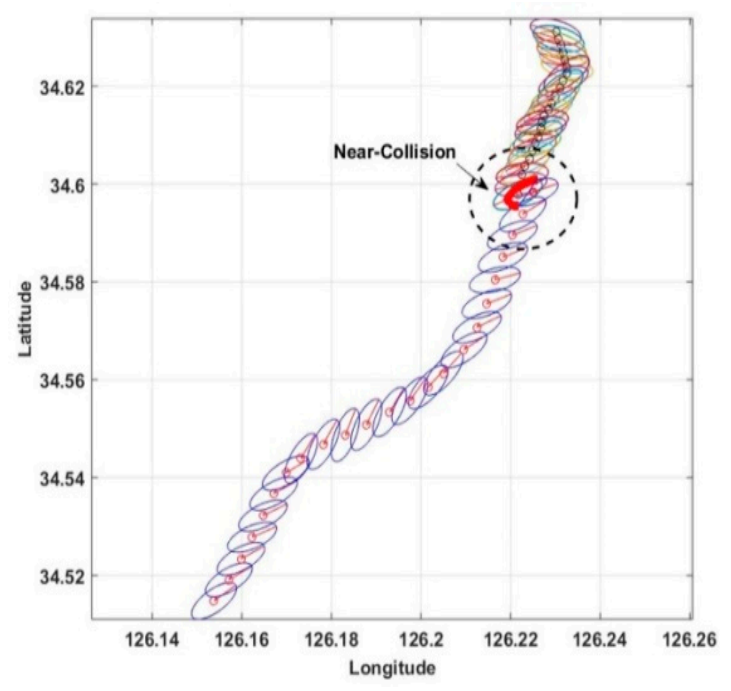

(d)

Figure 14. Encounter situation between the OS and the TS: (a) head-on situation at relative distance "6.86 nm"; (b) head-on situation at relative distance " $4.75 \mathrm{~nm}$ "; (c) head-on situation at relative distance “2.74 $\mathrm{nm}$ ", and (d) near-collision at relative distance " $0.75 \mathrm{~nm}$ ”.

The FOU size " $\pm 0 \%, \pm 5 \%, \pm 10 \%, \pm 15 \%, \pm 20 \%$, and $\pm 50 \%$ " were measured by the linear $R_{c}$ as shown in Figure 15 and Table 4 . On the other hand, the FOU size " $\pm 25 \%, \pm 30 \%, \pm 35 \%, \pm 40 \%$, and $\pm 45 \%$ " were measured by the non-linear $R_{c}$ as presented in Figure 16 and Table 5 . At the initial encounter situation between the OS and the TS, the FOU size " $\pm 0 \%, \pm 5 \%, \pm 10 \%, \pm 15 \%, \pm 20 \%$, and $\pm 50 \%$ " inferred the $R_{c} 0.00,0.01,0.01,0.00,0.00$, and 0.16 , respectively. The FOU size " $\pm 25 \%, \pm 30 \%, \pm 35 \%, \pm 40 \%$, and $\pm 45 \%$ " inferred the $R_{c} 0.00$. When it comes to a point of time for a give-away vessel (i.e., $R_{c} 0.33$ ), the computed linear $R_{\mathcal{C}}$ based on the FOU size " $\pm 0 \%, \pm 5 \%, \pm 10 \%, \pm 15 \%, \pm 20 \%$, and $\pm 50 \%$ " gave the alarm at about $7.93 \mathrm{~nm}$ and $1800 \mathrm{~s}$ left until near-collision. The computed non-linear $R_{c}$ based on the FOU size " $\pm 25 \%, \pm 30 \%, \pm 35 \%, \pm 40 \%$, and $\pm 45 \%$ " gave the alarm at about $7.93 \mathrm{~nm}$ and $1800 \mathrm{~s}$, $7.57 \mathrm{~nm}$ and $1710 \mathrm{~s}, 7.57 \mathrm{~nm}$ and $1710 \mathrm{~s}, 6.86 \mathrm{~nm}$ and $1530 \mathrm{~s}$, and $7.21 \mathrm{~nm}$ and $1620 \mathrm{~s}$, respectively. In near-collision situation, the FOU size " $\pm 0 \%, \pm 5 \%, \pm 10 \%, \pm 15 \%, \pm 20 \%$, and $\pm 50 \%$ " computed the $R_{\mathcal{C}}$ $0.99,0.99,0.99,0.98,0.98$, and 0.97 , respectively. The FOU size " $\pm 25 \%, \pm 30 \%, \pm 35 \%, \pm 40 \%$, and $\pm 45 \%$ " computed the $R_{c} 0.98,0.98,0.98,0.97$, and 0.97 , respectively. 


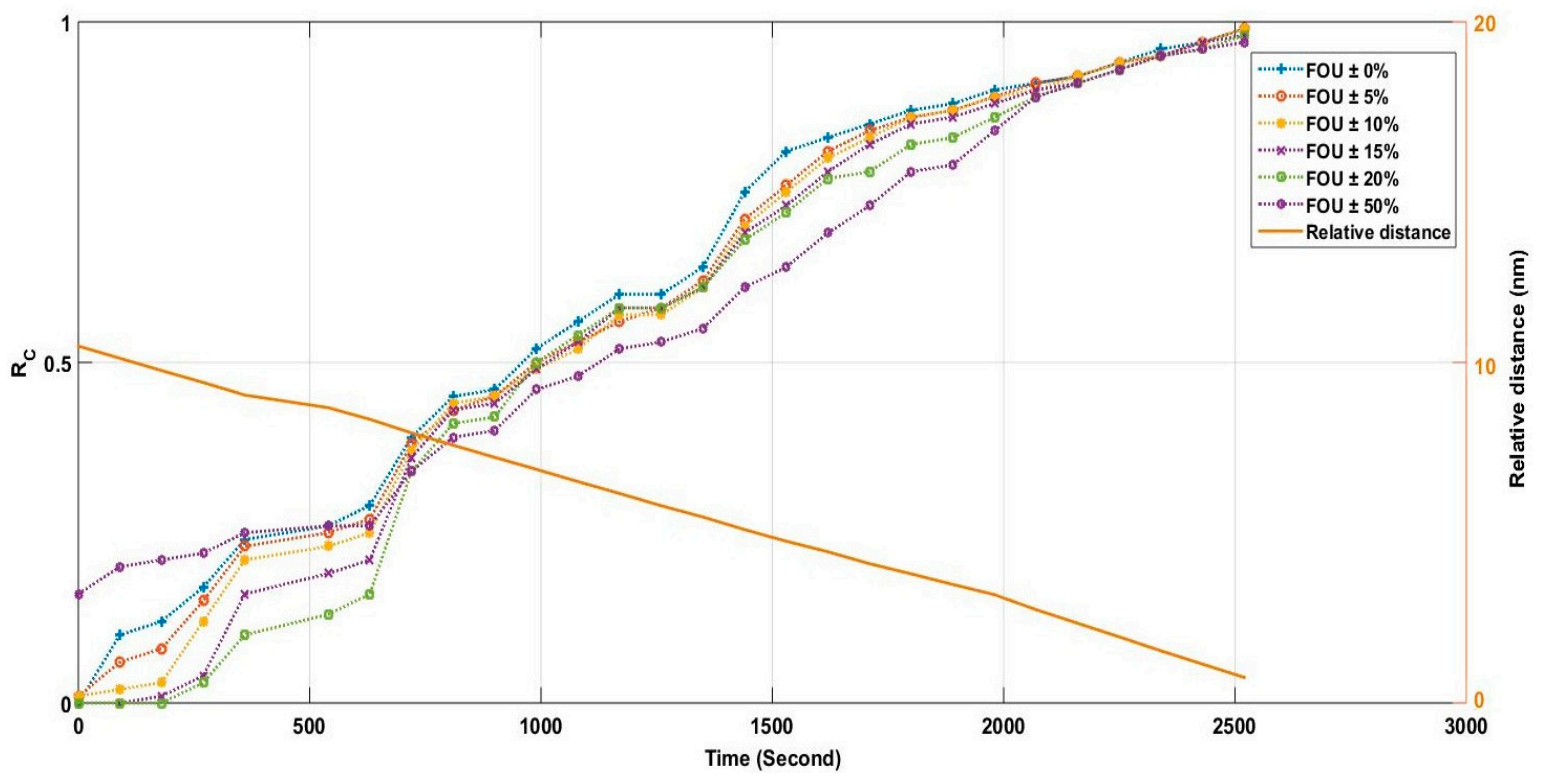

Figure 15. Linear $R_{c}$ by time and relative distance.

Table 4. Linear $R_{c}$ computed by different FOU size: background color is identical $R_{c}$.

\begin{tabular}{|c|c|c|c|c|c|c|c|c|c|}
\hline \multirow{2}{*}{ Time (s) } & \multirow{2}{*}{$\begin{array}{c}\text { Relative } \\
\text { Distance (nm) }\end{array}$} & \multirow{2}{*}{$D_{C P A} / \mathrm{L}$} & \multirow{2}{*}{$T_{C P A} /(\mathrm{L} / \mathrm{V})$} & \multicolumn{6}{|c|}{$R_{c}$ Computed by FOU Size } \\
\hline & & & & $\pm 0 \%$ & $\pm 5 \%$ & $\pm 10 \%$ & $\pm 15 \%$ & $\pm 20 \%$ & $\pm 50 \%$ \\
\hline 0 & 10.48 & 0.21 & 18.77 & 0.00 & 0.01 & 0.01 & 0.00 & 0.00 & 0.16 \\
\hline 90 & 10.12 & 0.22 & 16.13 & 0.10 & 0.06 & 0.02 & 0.00 & 0.00 & 0.20 \\
\hline 180 & 9.76 & 0.22 & 15.83 & 0.12 & 0.08 & 0.03 & 0.01 & 0.00 & 0.21 \\
\hline 270 & 9.41 & 0.21 & 14.59 & 0.17 & 0.15 & 0.12 & 0.04 & 0.03 & 0.22 \\
\hline 360 & 9.04 & 0.20 & 13.10 & 0.24 & 0.23 & 0.21 & 0.16 & 0.10 & 0.25 \\
\hline 540 & 8.67 & 0.20 & 12.81 & 0.26 & 0.25 & 0.23 & 0.19 & 0.13 & 0.26 \\
\hline 630 & 8.33 & 0.19 & 12.56 & 0.29 & 0.27 & 0.25 & 0.21 & 0.16 & 0.26 \\
\hline 720 & 7.93 & 0.18 & 11.08 & 0.39 & 0.38 & 0.37 & 0.36 & 0.34 & 0.34 \\
\hline 810 & 7.57 & 0.18 & 10.27 & 0.46 & 0.43 & 0.44 & 0.43 & 0.41 & 0.39 \\
\hline 900 & 7.21 & 0.17 & 10.13 & 0.46 & 0.45 & 0.44 & 0.44 & 0.42 & 0.40 \\
\hline 990 & 6.86 & 0.16 & 9.31 & 0.52 & 0.50 & 0.49 & 0.49 & 0.50 & 0.46 \\
\hline 1080 & 6.5 & 0.15 & 8.91 & 0.56 & 0.53 & 0.52 & 0.53 & 0.54 & 0.48 \\
\hline 1170 & 6.15 & 0.15 & 8.41 & 0.60 & 0.56 & 0.57 & 0.58 & 0.58 & 0.52 \\
\hline 1260 & 5.79 & 0.13 & 8.40 & 0.60 & 0.58 & 0.57 & 0.58 & 0.58 & 0.53 \\
\hline 1350 & 5.46 & 0.13 & 8.06 & 0.64 & 0.65 & 0.61 & 0.61 & 0.61 & 0.55 \\
\hline 1440 & 5.09 & 0.12 & 7.22 & 0.75 & 0.71 & 0.70 & 0.69 & 0.68 & 0.61 \\
\hline 1530 & 4.75 & 0.12 & 6.74 & 0.81 & 0.76 & 0.75 & 0.73 & 0.72 & 0.64 \\
\hline 1620 & 4.44 & 0.11 & 6.11 & 0.83 & 0.81 & 0.80 & 0.78 & 0.77 & 0.69 \\
\hline 1710 & 4.09 & 0.10 & 5.47 & 0.85 & 0.84 & 0.83 & 0.82 & 0.78 & 0.73 \\
\hline 1800 & 3.79 & 0.09 & 4.78 & 0.87 & 0.86 & 0.86 & 0.85 & 0.82 & 0.78 \\
\hline 1890 & 3.48 & 0.08 & 4.63 & 0.88 & 0.87 & 0.87 & 0.86 & 0.83 & 0.79 \\
\hline 1980 & 3.18 & 0.07 & 4.09 & 0.90 & 0.89 & 0.89 & 0.88 & 0.86 & 0.84 \\
\hline 2070 & 2.74 & 0.06 & 3.59 & 0.90 & 0.91 & 0.90 & 0.90 & 0.89 & 0.89 \\
\hline 2160 & 2.34 & 0.05 & 3.29 & 0.92 & 0.92 & 0.92 & 0.91 & 0.91 & 0.91 \\
\hline 2250 & 1.94 & 0.04 & 2.71 & 0.94 & 0.94 & 0.94 & 0.93 & 0.93 & 0.93 \\
\hline 2340 & 1.53 & 0.03 & 2.11 & 0.96 & 0.95 & 0.95 & 0.95 & 0.95 & 0.95 \\
\hline 2430 & 1.14 & 0.02 & 1.65 & 0.97 & 0.97 & 0.97 & 0.97 & 0.96 & 0.96 \\
\hline 2520 & 0.75 & 0.00 & 1.15 & 0.99 & 0.99 & 0.99 & 0.98 & 0.98 & 0.97 \\
\hline
\end{tabular}




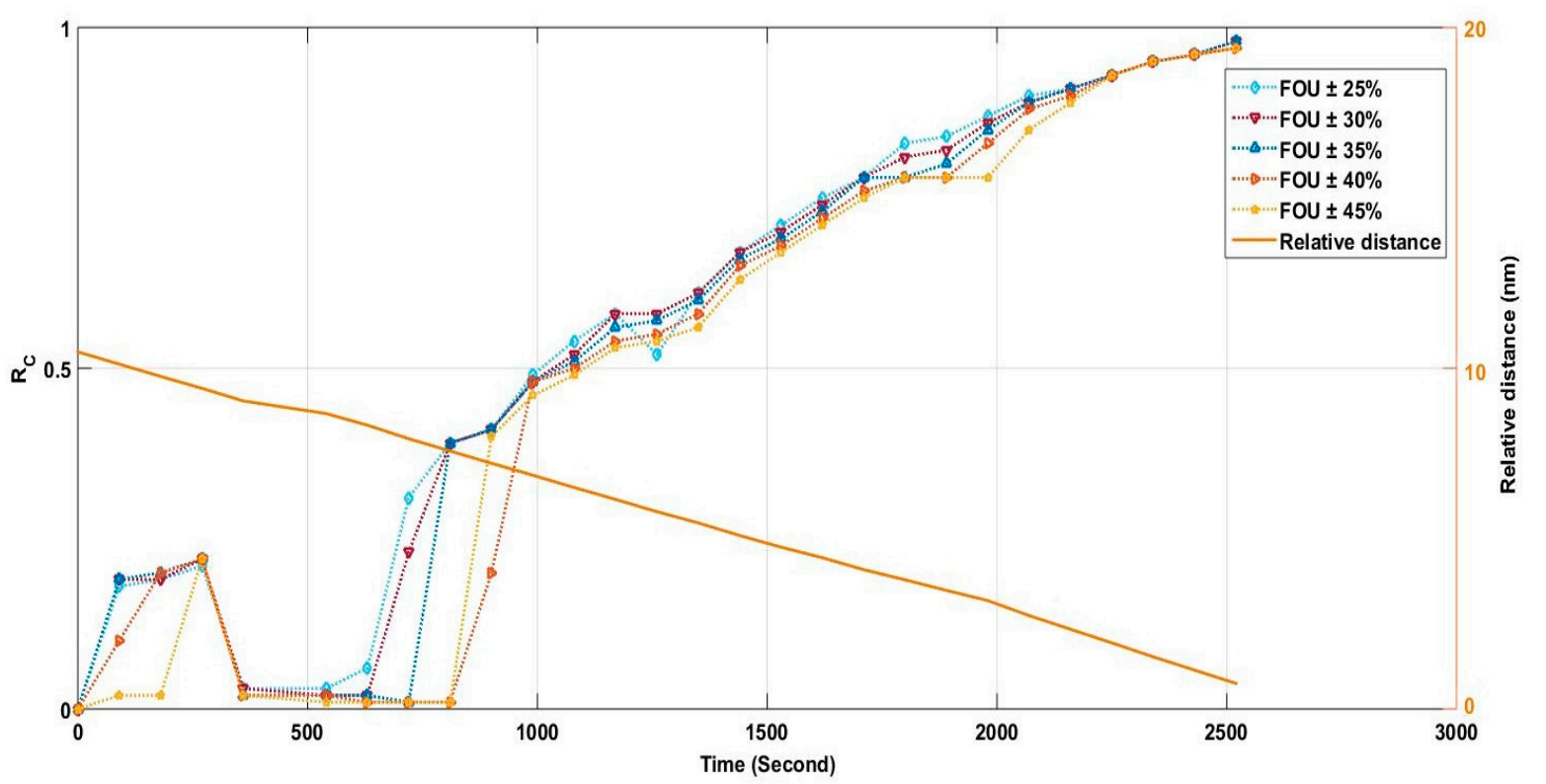

Figure 16. Non-linear $R_{c}$ by time and relative distance.

Table 5. Non-linear $R_{c}$ computed by different FOU size: background color is identical $R_{c}$.

\begin{tabular}{|c|c|c|c|c|c|c|c|c|}
\hline \multirow{2}{*}{ Time (s) } & \multirow{2}{*}{$\begin{array}{l}\text { Relative Distance } \\
\text { (nm) }\end{array}$} & \multirow{2}{*}{$D_{C P A} / \mathrm{L}$} & \multirow{2}{*}{$T_{C P A} /(\mathrm{L} / \mathrm{V})$} & \multicolumn{5}{|c|}{$R_{c}$ Computed by FOU Size } \\
\hline & & & & $\pm 25 \%$ & $\pm 30 \%$ & $\pm 35 \%$ & $\pm 40 \%$ & $\pm 45 \%$ \\
\hline 0 & 10.48 & 0.21 & 18.77 & 0.00 & 0.00 & 0.00 & 0.00 & 0.00 \\
\hline 90 & 10.12 & 0.22 & 16.13 & 0.18 & 0.19 & 0.19 & 0.10 & 0.02 \\
\hline 180 & 9.76 & 0.22 & 15.83 & 0.19 & 0.19 & 0.20 & 0.20 & 0.02 \\
\hline 270 & 9.41 & 0.21 & 14.59 & 0.21 & 0.22 & 0.22 & 0.22 & 0.22 \\
\hline 360 & 9.04 & 0.20 & 13.10 & 0.03 & 0.03 & 0.02 & 0.02 & 0.02 \\
\hline 540 & 8.67 & 0.20 & 12.81 & 0.03 & 0.02 & 0.02 & 0.02 & 0.01 \\
\hline 630 & 8.33 & 0.19 & 12.56 & 0.06 & 0.02 & 0.02 & 0.01 & 0.01 \\
\hline 720 & 7.93 & 0.18 & 11.08 & 0.31 & 0.23 & 0.01 & 0.01 & 0.01 \\
\hline 810 & 7.57 & 0.18 & 10.27 & 0.39 & 0.39 & 0.39 & 0.01 & 0.01 \\
\hline 900 & 7.21 & 0.17 & 10.13 & 0.41 & 0.41 & 0.41 & 0.20 & 0.40 \\
\hline 990 & 6.86 & 0.16 & 9.31 & 0.49 & 0.48 & 0.48 & 0.48 & 0.46 \\
\hline 1080 & 6.5 & 0.15 & 8.91 & 0.54 & 0.52 & 0.51 & 0.50 & 0.49 \\
\hline 1170 & 6.15 & 0.15 & 8.41 & 0.58 & 0.58 & 0.56 & 0.54 & 0.53 \\
\hline 1260 & 5.79 & 0.13 & 8.40 & 0.52 & 0.58 & 0.57 & 0.55 & 0.54 \\
\hline 1350 & 5.46 & 0.13 & 8.06 & 0.61 & 0.61 & 0.60 & 0.58 & 0.56 \\
\hline 1440 & 5.09 & 0.12 & 7.22 & 0.67 & 0.67 & 0.66 & 0.65 & 0.64 \\
\hline 1530 & 4.75 & 0.12 & 6.74 & 0.71 & 0.70 & 0.69 & 0.68 & 0.68 \\
\hline 1620 & 4.44 & 0.11 & 6.11 & 0.75 & 0.74 & 0.73 & 0.72 & 0.71 \\
\hline 1710 & 4.09 & 0.10 & 5.47 & 0.78 & 0.78 & 0.78 & 0.76 & 0.75 \\
\hline 1800 & 3.79 & 0.09 & 4.78 & 0.83 & 0.81 & 0.78 & 0.78 & 0.78 \\
\hline 1890 & 3.48 & 0.08 & 4.63 & 0.84 & 0.82 & 0.80 & 0.78 & 0.78 \\
\hline 1980 & 3.18 & 0.07 & 4.09 & 0.87 & 0.86 & 0.85 & 0.83 & 0.78 \\
\hline 2070 & 2.74 & 0.06 & 3.59 & 0.90 & 0.89 & 0.89 & 0.88 & 0.85 \\
\hline 2160 & 2.34 & 0.05 & 3.29 & 0.91 & 0.91 & 0.91 & 0.90 & 0.89 \\
\hline 2250 & 1.94 & 0.04 & 2.71 & 0.93 & 0.93 & 0.93 & 0.93 & 0.93 \\
\hline 2340 & 1.53 & 0.03 & 2.11 & 0.95 & 0.95 & 0.95 & 0.95 & 0.95 \\
\hline 2430 & 1.14 & 0.02 & 1.65 & 0.96 & 0.96 & 0.96 & 0.96 & 0.96 \\
\hline 2520 & 0.75 & 0.00 & 1.15 & 0.98 & 0.98 & 0.98 & 0.97 & 0.97 \\
\hline
\end{tabular}

\subsection{Discussion}

In Section 4.1, it could be seen that the IT2FISs generated by gradually increasing the FOU size over a number of steps from " $\pm 0 \%$ " to " $\pm 50 \%$ " were able to compute $R_{c}$ as linear-type and non-linear-type. 
In addition, they gave the collision avoidance alarm depending on the give-way vessel in accordance with the COLREGs [2]. In this section, the measured linear and non-linear $R_{c}$ according to numerical changing of input parameters, are discussed, as well as comparison with the existing FIS $[16,17]$ as presented in Figure 17, which is a numerical simulation result conducted in a state of Section 4.1.

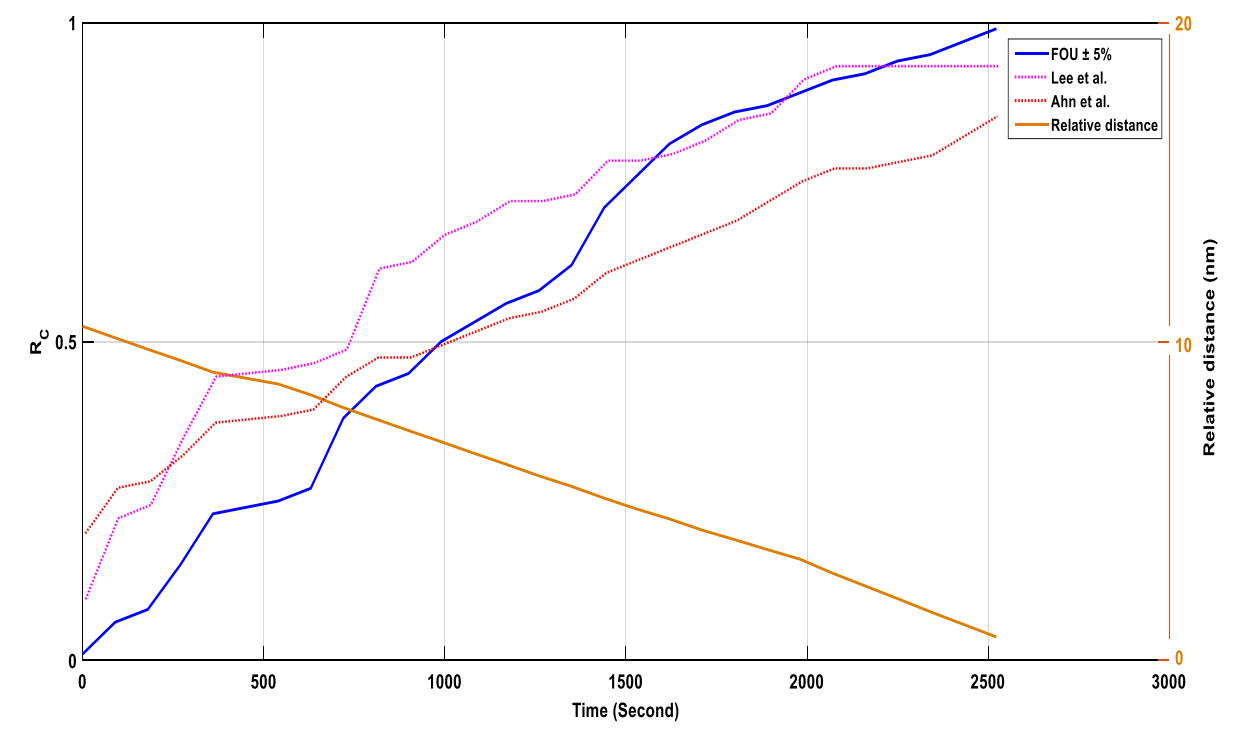

Figure 17. Comparison of the IT2FIS based on FOU size “ $\pm 5 \%$ " and the existing FIS.

In terms of the measured linear and non-linear $R_{c}$, though a total of the measured $R_{c}$ should be gradually increased according to a reduction of both inputs $D_{C P A} / L$ and $T_{C P A} /(L / V)$, the FOU size " $\pm 25 \%, \pm 30 \%, \pm 35 \%, \pm 40 \%$, and $\pm 45 \%$ " computed repeated increase and decrease $R_{c}$ in encounter situation between the OS and the TS. Accordingly, it is expected to be difficult that navigators make a decision for collision avoidance. On the other hand, as for the $R_{c}$ measured by the FOU size " $\pm 0 \%$, $\pm 5 \%, \pm 10 \%, \pm 15 \%, \pm 20 \%$, and $\pm 50 \% "$, state of repeated increase and decrease $R_{c}$ did not exist in. Likewise, the existing FIS $[16,17]$ did also not compute $R_{c}$ in a state of repeated increase and decrease. Nonetheless, the FOU size " $\pm 0 \%, \pm 10 \%, \pm 15 \%, \pm 20 \%$, and $\pm 50 \%$ " and the existing FIS [16,17] computed identical $R_{C}$ according to changing $D_{C P A} / L$ and $T_{C P A} /(L / V)$. However, the $R_{c}$ computed by the FOU size “ $\pm 5 \%$ " only was various according to changing parameters.

According to rule 8 and 16 in COLREGs, the give-way vessel needs to take early action for collision avoidance. Accordingly, ship using the IT2FISs based on FOU size " $\pm 0 \%, \pm 5 \%, \pm 10 \%, \pm 15 \%, \pm 20 \%$, and $\pm 50 \%$ " could be possible that they early detect the collision risk faster than the IT2FISs based on the FOU size " $\pm 25 \%, \pm 30 \%, \pm 35 \%, \pm 40 \%$, and $\pm 45 \%$ " and the existing FIS [16,17]. At this time, a point of time for a give-way vessel using the existing FIS is 0.60 , on the other hand, IT2FISs generated by gradually increasing the FOU size over a number of steps from " $\pm 0 \%$ " to " $\pm 50 \%$ " is 0.33 due to extension of the T1FIS-NC.

For this reason, a ship using the IT2FIS based on the FOU size " $\pm 5 \%$ " would be able to take early action for collision avoidance at an appropriate point of positioning and timing via various measured linear $R_{c}$ according to changing of input parameters.

\section{Conclusions}

In this paper, we developed the IT2FIS as an extension of the T1FIS-NC, and focused the FOU size taking account of symmetry. We have conducted numerical simulation by applying IT2FISs by the gradually increased FOU to ships navigating with different maneuverability in the actual sea area. As a result of comparison of the IT2FISs and the existing FIS, we were able to analyze that IT2FIS using the FOU size " $\pm 5 \%$ " computed various and appropriate $C R I$ by linear type until near-collision according to numerical changing of $D_{C P A} / L$ and $T_{C P A} /(L / V)$. Accordingly, the developed IT2FIS not 
only overcame the issues pointed out, which did not take into consideration numerical uncertainties in changing circumstances, but also the navigator can make an appropriate decision for collision avoidance by computing $C R I$ in appropriate positioning and timing. In the near future, we are looking forward to extending our work on path planning for collision avoidance by computing the CRI based on developed IT2FIS, and validate smooth trajectory, reduction of path deviation, and saving time (i.e., the time to get to target point from reduction of path deviation after taking an action for collision avoidance).

Author Contributions: Conceptualization, H.N.; methodology, S.W.O.; Software, H.N.; Validation, S.W.O. and H.N.; Writing-Original Draft Preparation, S.W.O.; Writing-Review and Editing, H.N.; Supervision, H.N. All authors have read and agreed to the published version of the manuscript.

Funding: This research received no external funding.

Conflicts of Interest: The authors declare no conflict of interest.

\section{References}

1. Korean Maritime Safety Tribunal, Annual Report of Marine Accident. 2019. Available online: http: //www.kmst.go.kr/kmst/statistics/annualReport/selecAnnReportList.do (accessed on 23 January 2020).

2. IMO. Convention on the International Regulations for Preventing Collisions at Sea, 8th ed.; International Maritime Organization: London, UK, 1972.

3. Fujii, Y.; Tanaka, K. Studies in marine traffic engineering: Traffic capacity. J. Navig. 1971, 24, 543-552. [CrossRef]

4. Goodwin, E.M. A statistical study of ship domains. J. Navig. 1975, 28, 328-344. [CrossRef]

5. Davis, P.V.; Dove, M.J.; Stockel, C.T. A computer simulation of marine traffic using domains and arenas. J. Navig. 1980, 33, 215-222. [CrossRef]

6. Coldwell, T.G. Marine traffic behaviour in restricted waters. J. Navig. 1983, 36, 430-444. [CrossRef]

7. Smierzchalski, R. Ship's Domains as a Collision Risk at Sea in the Evolutionary Trajectory Planning. In Proceedings of the Computer Simulation in Risk Analysis and Hazard Mitigation (RISK ANALYSIS 2000), Southampton, UK, 11-13 October 2000.

8. Kijima, K.; Furukawa, Y. Automatic Collision Avoidance System using the Concept of Blocking Area. In Proceedings of the IFAC Conference on Manoeuvring and Control of Marine Craft, Girona, Spain, 17-19 September 2003.

9. Hansen, M.G.; Jensen, T.K.; Lehn-Schiøler, T.; Melchild, K.; Rasmussen, F.M.; Ennemark, F. Empirical Ship Domain Based on AIS Data. J. Navig. 2013, 66, 931-940. [CrossRef]

10. Wang, Y.; Chin, H.-C. An Empirically-Calibrated Ship Domain as a Safety Criterion for Navigation in Confined Waters. J. Navig. 2016, 69, 257-276. [CrossRef]

11. Szlapczynski, R.; Szlapczynska, J. Review of Ship Safety Domains: Models and Applications. Ocean Eng. 2017, 145, 277-289. [CrossRef]

12. Kearon, J. Computer Program for Collision Avoidance and Track Keeping. In Proceedings of the Conference on Mathematics Aspects of Marine Traffic, London, UK, 15-16 September 1977.

13. Smeaton, G.P.; Coenen, F.P. Developing an Intelligent Marine Navigation System. Comput. Control Eng. J. 1990, 1, 95-103. [CrossRef]

14. Lisowski, J. Game Control of Moving Objects. In Proceedings of the IFAC 15th Triennial World Congress, Barcelona, Spain, 21-26 July 2002.

15. Hasekawa, K.; Kouzyki, A.; Muramatsu, T.; Komine, H.; Watabe, Y. Ship Auto-navigation Fuzzy Expert System (SAFES). J. Soc. Nav. Arch. Jpn. 1989, 1989, 445-452. [CrossRef]

16. Lee, H.-J.; Rhee, K.-P. Development of Collision Avoidance System by using Expert System and Search Algorithm. Int. Shipbuiding Prog. 2001, 48, 197-212.

17. Ahn, J.-H.; Rhee, K.-P.; You, Y.-J. A Study on the Collision Avoidance of a Ship using Neural Networks and Fuzzy Logic. Appl. Ocean Res. 2012, 37, 162-173. [CrossRef]

18. Bukhari, A.C.; Tusseyeva, I.; Lee, B.-G.; Kim, Y.-G. An Intelligent Real-Time Multi-Vessel Collision Risk Assessment System from VTS View Point based on Fuzzy Inference System. Expert Syst. Appl. 2013, 40, 1220-1230. [CrossRef] 
19. Namgung, H. Inference Rule of Collision Risk Index based on Ship Near-Collision via Adaptive Neuro Fuzzy Inference System. Adv. Sci. Technol. Eng. Syst. J. 2019, 4, 152-160. [CrossRef]

20. Zadeh, L.A. The Concept of a Linguistic Variable and its Application to Approximate Reasoning-I. Inf. Sci. 1975, 8, 199-249. [CrossRef]

21. Karnik, N.N.; Mendel, J.M.; Liang, Q. Type-2 fuzzy logic systems. IEEE Trans. Fuzzy Syst. 1999, 7, $643-658$. [CrossRef]

22. Liang, Q.; Mendel, J.M. Interval Type-2 Fuzzy Logic System: Theory and Design. IEEE Trans. Fuzzy Syst. 2000, 8, 535-550. [CrossRef]

23. Wagner, C.; Hagras, H. A Genetic Algorithm based Architecture for Evolving Type-2 Fuzzy Logic Controller for Real World Autonomous Mobile Robots. In Proceedings of the 2007 IEEE International Fuzzy Systems Conference, London, UK, 23-26 July 2007.

24. Baklouti, N.; John, R.; Alimi, A.M. Interval Type-2 Fuzzy Logic Control of Mobile Robots. J. Intell. Learn. Syst. Appl. 2012, 4, 291-302. [CrossRef]

25. Castillo, O.; Martínez-Marroquín, R.; Melin, P.; Valdez, F.; Soria, J. Comparative Study of Bio-inspired Algorithms Applied to the Optimization of Type-1 and Type-2 Fuzzy Controllers for an Autonomous Mobile Robot. Inf. Sci. 2012, 192, 19-38. [CrossRef]

26. Naafia, N.; El Kari, A.; Ayad, H.; Mjahed, M. Robust Interval Type-2 Fuzzy Sliding Mode Control Design for Robot Manipulators. Robotics 2018, 7, 40. [CrossRef]

27. Ren, G.-P.; Chen, Z.; Zhang, H.-T.; Wu, Y.; Meng, H.; Wu, D.; Ding, H. Design of Interval Type-2 Fuzzy Controllers for Active Magnetic Bearing Systems. IEEE/ASME Trans. Mechatron. 2020. [CrossRef]

28. Mao, W.-L.; Shiu, D.-Y. Precision Trajectory Tracking on XY Motion Stage Using Robust Interval Type-2 Fuzzy PI Sliding Mode Control Method. Int. J. Precis. Eng. Manuf. 2020, 21, 797-818. [CrossRef]

29. Zhao, T.; Xiang, Y.; Dian, S.; Guo, R.; Li, S. Hierarchical Interval Type-2 Fuzzy Path Planning based on Genetic Optimization. J. Intell. Fuzzy Syst. 2020, 1-12. [CrossRef]

30. Zadeh, L.A. Fuzzy Sets. Inf. Control 1965, 8, 338-353. [CrossRef]

31. Cockcroft, A.N.; Lameijer, J.N.F. A Guide to the Collision Avoidance Rules, 7th ed.; Butterworth Heinemann: Oxford, UK, 2011; pp. 1-183.

(C) 2020 by the authors. Licensee MDPI, Basel, Switzerland. This article is an open access article distributed under the terms and conditions of the Creative Commons Attribution (CC BY) license (http://creativecommons.org/licenses/by/4.0/). 